\title{
Clinical and Social Concerns in Treated Patients with Primary Hypothyroidism in Basrah: A Cross Sectional Study
}

\author{
Haider Ayad Alidrisi ${ }^{1}$, Alaa Khattar Musa², Abbas Ali Mansour ${ }^{1 .}$ * \\ ${ }^{1}$ Al-Faiha Specialized Diabetes, Endocrine and Metabolism Center (FDEMC), Basrah College of Medicine, Basrah, Iraq \\ ${ }^{2}$ Department of Medicine, Basrah College of Medicine, Basrah, Iraq
}

Email address:

aambaam@gmail.com (A. A. Mansour)

\section{To cite this article:}

Haider Ayad Alidrisi, Alaa Khattar Musa, Abbas Ali Mansour. Clinical and Social Concerns in Treated Patients with Primary Hypothyroidism in Basrah: A Cross Sectional Study. American Journal of Internal Medicine. Vol. 3, No. 6, 2015, pp. 256-263.

doi: 10.11648/j.ajim.20150306.17

\begin{abstract}
Background: Despite available treatment for hypothyroidism, L-thyroxine replacement therapy in a biochemically appropriate dose does not necessarily relieve patients' symptoms and complaints. The aim of the study was to evaluate the concerns of patients treated with hypothyroidism and to correlate these concerns with different patient characteristics and thyroid biochemical control. Subjects and Methods: one hundred eighteen treated primary hypothyroid patients attending Al-Faiha Specialized Diabetes, Endocrine and Metabolism Center (FDEMC) in Al-Basrah were entering a questionnaire designed to capture personal, anthropometric, biochemical and clinical data. Twenty-four concerns were questioned to the patients who score these concerns on a 4 point Likert scale. Results: The most scored patients' concerns were fatigue, neuropathic pain, lack of weight loss, cold intolerance, breathing problems, and swallowing problems. No statistically significant relations were existed between these concerns and thyroid stimulating hormone (TSH) control, except for a high TSH group which were highly likely to have concerns of feeling sick (OR: $0.27,95 \% \mathrm{CI} 0.54$ to $2.0, \mathrm{p}=0.001)$, neuropathic pain (OR: $0.4,95 \% \mathrm{CI} 0.17$ to $1.6, \mathrm{p}=0.01)$, cold intolerance (OR: $0.35,95 \%$ CI 0.0 .3 to $1.7, \mathrm{p}=0.005$ ), and hair problems (OR: $0.26,95 \% \mathrm{CI} 0.6$ to $2.1, \mathrm{P}<0.0001$ ). A significant correlation existed between duration of the hypothyroidism and patients' concerns of swelling of the hands and feet $(\mathrm{R}=0.7 \mathrm{P}<0.0001)$, memory problems $(\mathrm{R}=0.4 \mathrm{P}<0.0001)$, hearing disturbance $(\mathrm{R}=0.38 \mathrm{P}<0.0001)$, and hair problems $(\mathrm{R}=0.3$ $\mathrm{P}=0.001)$. Age significantly affects patients' concerns of memory problems $(\mathrm{R}=0.6 \mathrm{P}<0.0001)$, swelling of the hands and feet $(\mathrm{R}=0.4 \mathrm{P}<0.0001)$, and hearing disturbance $(\mathrm{R}=0.37 \mathrm{P}<0.0001)$. Positive correlation was present between low density lipoprotein cholesterol level and patients' concerns of cold intolerance $(\mathrm{R}=0.3 \mathrm{P}=0.001)$, hair problems $(\mathrm{R}=0.28 \mathrm{P}=0.003)$, feeling sick $(\mathrm{R}=0$. $2 \mathrm{P}=0.02)$, and neuropathic pain $(\mathrm{R}=0.18 \mathrm{P}=0.04)$. The total cholesterol level also showed a positive correlation with patients' concerns of cold intolerance $(\mathrm{R}=0.3 \mathrm{P}=0.001)$, hair problems $(\mathrm{R}=0.25 \mathrm{P}=0.01)$, neuropathic pain $(\mathrm{R}=0.22 \mathrm{P}=0$. 01$)$, and fatigue $(\mathrm{R}=0.2 \mathrm{P}=0.04)$. Conclusion: We cannot rely on the TSH level alone as a marker of optimal treatment outcome in patients with primary hypothyroidism because it does not reflect the concern status of the patients.
\end{abstract}

Keywords: Hypothyroidism, Patients' Concerns, Thyroid Stimulating Hormone

\section{Introduction}

Hypothyroidism is one of the most common endocrine disorders, with a greater burden of disease in women and elderly [1]. A prevalence rate of $2-5 \%$ has been reported throughout the world, with a frequency that differs from one society to another [2].

It manifests different levels of severity and variably presents between patients which results in a wide interindividual range of clinical and biochemical signs and symptoms [3].

The replacement of thyroxine in a biochemically suitable dose does not necessarily improve the patient of these symptoms. Some patients have persistent psychological symptoms while some tend to complain of physical symptoms as well. Others state that they just feel abnormal in spite of ongoing therapy [4].

Some patients report inadequate weight loss or continuous weight gain[5], difficulty in remembering, cannot think of the 
right word, feeling tired and lethargic, and feeling aches and pains all over the body in spite of normal TSH levels [6-11].

The aim of this study was to evaluate the concerns of patients who are treated for hypothyroidism and to correlate these concerns in relation to patient's characteristics and thyroid biochemical control.

\section{Subjects and Methods}

This study was conducted at a single Center crosssectional evaluation involving primary hypothyroid patients attending Al-Faiha Specialized Diabetes, Endocrine and Metabolism Center (FDEMC) in Basrah from February to June 2014. After taking consent, one hundred eighteen treated hypothyroid patients aged from eighteen to seventy years were entered a questionnaire designed to capture personal, anthropometric, biochemical and clinical data.

Patients excluded from the study include those with thyroidectomy or radioactive iodine therapy for thyroid diseases, secondary hypothyroidism, severe medical illnesses, pregnant patients, severe depression and psychological disorders, and those who were not interested with the questionnaire. Further, twenty four concerns were raised by the patients, these concerns were based on the main domains of Thyroid Related Quality of Life [12], Thyroid Symptom Questionnaire [6] and a similar study was done to assess the concerns of treated hypothyroid patients [13]. No available questionnaire has the potential to cover all aspects relevant to patients in longitudinal studies, they all lack a thorough validation. [14]

\subsection{These Concerns Were Grouped into the Following (Appendix)}

General health related concerns:

Fatigue (exhausted, tired, difficult to be motivated).

Feeling sick.

Lack of weight loss.

Neuropathic pain (unusual burning, tingling sensation).

Hearing disturbances.

Cold intolerance.

Skin dryness.

Constipation.

Swelling of hands and feet.

Hair problems (loss or thinning).

Depression (sadness, loss of interest, difficult to be motivated).

Memory problems (difficulty in remembering things).

Sexual life concerns (Impaired sex life and reduced sex desire).

Neck related symptoms:

Swallowing problems (like globus sensation, discomfort and difficulty).

Breathing problems (like snoring, sleep apnea).

Cosmetic goiter concern.

Gynecologic concerns:

Menstrual disturbances.

Recurrent pregnancy loss.
Fertility concerns (both males and females).

Drug related concerns:

Permanent medications.

Side effects (hunger, palpitation).

Interactions.

Social concerns:

Marital concern.

Financial concern.

Following questioning, each patient was asked to score these concerns on 4 point Likert scale in which a higher score means a greater degree of concerns a particular symptom, medical or social issues as shown in the appendix.

\subsection{Anthropometric Measurements}

Each Patient was examined for height, weight, and body mass index (BMI) was calculated by the formula of (weight in $\mathrm{kg} /$ height $\mathrm{m} 2$ ). According to the World Health Organization, values of BMI less than $25 \mathrm{~kg} / \mathrm{m} 2$ were regarded as normal, and values of BMI greater than or equal to $25 \mathrm{~kg} / \mathrm{m} 2$ were used to define overweight. Blood pressure was measured using a standard mercury sphygmomanometer and hypertension was labeled if blood pressure $\geq 140 \mathrm{mmHg}$ systolic blood pressure and $\geq 90 \mathrm{~mm} \mathrm{Hg}$ diastolic blood pressure or known to be hypertensive on treatment.

\subsection{Biochemical Measurements}

From each patient, $10 \mathrm{ml}$ of blood was taken, centrifuged immediately after drawing blood and serum was stored for analysis.

Thyroid stimulating hormone (TSH) was analysed by Electro-Chemi Luminescence (ECL) assay (cobas e 411 analyzer - Roche,Germany). The TSH assay had an analytical sensitivity of $0.025 \mathrm{mIU} / \mathrm{l}$, with a normal range of $0 \cdot 17-5 \cdot 2$ $\mathrm{mIU} / \mathrm{l}$. The range of measurement was $0.005-100.0 \mathrm{mIU} / \mathrm{L}$, reference range was $0.27-4.2 \mathrm{mIU} / \mathrm{L}$ intra-assay $<2 \% \mathrm{CV}$ and interassay $<4 \% \mathrm{CV}$. Patients with TSH level $(>4.2$ $\mathrm{mIU} / \mathrm{l})$ were considered high.

Glycated hemoglobin (HbAlc) was measured by ion exchange high performance liquid chromatography (HPLC) using a Biorad D10.

Fasting lipid profile and fasting plasma glucose were done after 8-12 hours fasting state using Biolyzer ${ }^{\circledR} 300$, Germany.

\subsection{Statistical Analysis}

The Statistical Package for the Social Sciences Version 15.0. was used for analysis. Independent Student's t-test and Ordinal Logistic Regression Analysis were used for comparison in between groups. Ordinal Logistic Regression Analysis was used to assess patients' concerns ordinal responses in relation to the TSH control. The coefficients and the Odd ratio (OR) were for the group of high TSH. For any score of patients' concerns in this group, OR of less than one $(<1)$ means they score these concerns higher than patients with normal TSH (highest cumulative scores more likely). While an OR of more than one $(>1)$ means they score these concerns lower than patients with normal TSH 
(lower cumulative scores more likely). Pearson's correlation coefficient ( $\mathrm{R}$ value) was calculated to test the association between continuous variables. For all the tests performed, the results were considered statistically significant if $\mathrm{P}<0.05$.

\section{Results}

One hundred eighteen hypothyroid patient out of which $112(94.9 \%)$ were females and $6(5.1 \%)$ males. The mean age was $46.2 \pm 15.4$ years, with $94(79.9 \%)$ were married (table$1)$. Of them, 24 patients $(20.3 \%)$ were hypertensive on treatment. Fifty six $(47.5 \%)$ patients were diabetic (of them, 6 patients were newly discovered.

Table 1. Anthropometric and metabolic characteristics $(N=118)$.

\begin{tabular}{ll}
\hline Variable & $\begin{array}{l}\text { Mean (Std. Deviation) } \\
\text { unless stated }\end{array}$ \\
\hline Age (years) No. (\%) & $46.2(15.4)$ \\
Body mass index (kg/m2) & $31.9(6.4)$ \\
Hypertension No. (\%) & $24(20.3 \%)$ \\
Systolic blood pressure(mmHg) & $132.0(20.5)$ \\
Diastolic blood pressure(mmHg) & $81.3(10)$ \\
Diabetes mellitus No. (\%) & $56(47.5)$ \\
Fasting plasma glucose (mg/dl) & $133.4(42.3)$ \\
HbAlc \% for all & $6.9(2.3)$ \\
Fasting plasma glucose (mg/dl) for diabetic & $160(46.7)$ \\
patients & $8.7(2.2)$ \\
HbAlc \%for diabetic patients & $109.0(5.4)$ \\
Fasting plasma glucose (mg/dl) for non- & $5.3(0.4)$ \\
diabetics & $121.7(36.3)$ \\
HbAlc \%for non-diabetics & $45.7(16.2)$ \\
Low density lipoprotein-C (LDL-C) mg/dl) & $35.3(16.5)$ \\
High density lipoprotein-C(HDL-C) mg/dl & $204.9(47.7)$ \\
Very low density lipoprotein-C(VLDL-C) mg/dl & $164.5(73)$ \\
Total cholesterol(TC) mg/dl & \\
Triglyceride (mg/dl) & \\
\hline
\end{tabular}

All patients had TSH value within the last month of interview (table-2). Thirty eight patients $(32.2 \%)$ had $\mathrm{TSH} \leq$
$4.2 \mathrm{mIU} / 1$ and 80 patients $(67.8 \%)$ had TSH $>4.2 \mathrm{mIU} / \mathrm{l}$. The mean age of patients with normal TSH and high TSH were $52 \pm 14.1$ years and $43.4 \pm 15.3$ years respectively. The mean duration of hypothyroidism in the 118 patients was $6.1 \pm 5.6$ years, with the minimal duration was a half year and the maximal duration was 25 years. All patients were on Lthyroxine given as a single daily dose. The dose range $25 \mathrm{mcg}-200 \mathrm{mcg} / \mathrm{day}$, with the mean dose $98.3 \pm 40.5 \mathrm{mcg} /$ day. About 90 patients $(76.3 \%)$ were taking the dose at the early morning half hour before breakfast, the remaining 28 patients $(23.7 \%)$ were taking their dose at other times of the day usually at bedtime.

As shown in table 1, the mean BMI for the patients was $31.9 \pm 6.4 \mathrm{~kg} / \mathrm{m} 2,20(17 \%)$ patients had normal BMI and 98 $(83 \%)$ were overweight. The mean BMI for patients with normal and high TSH were $31.2 \pm 5 \mathrm{~kg} / \mathrm{m} 2$ and $32.3 \pm 7 \mathrm{~kg} / \mathrm{m} 2$ respectively. There was no statistically significant difference in the prevalence of overweight in between normal and high TSH patient groups $(\mathrm{P}=0.54)$.

There was no statistical significant difference in the prevalence of T2DM between patients with normal $(57.9 \%)$ and high TSH level (50\%) (table-3). The mean HBA1c and fasting plasma glucose for the diabetic patients showed no significant difference between these patient groups. The frequency of above target HBA1c in diabetic patients was $(75 \%)$ in patients with normal TSH and $(85 \%)$ in those with high $\mathrm{TSH}$, again with no statistical significance.

As shown in figure-1, the means for Low-density lipoprotein cholesterol (LDL-C), high-density lipoprotein cholesterol (HDL-C), very low density lipoprotein cholesterol (VLDL-C), total cholesterol levels (TC), and triglyceride (TG) levels were higher in patients with high TSH than those with normal TSH. Although it was not significant for HDL-C, VLDL-C, and TG, the difference was statistically significant in both LDL-C $(\mathrm{P}=0$. 001) and TC $(\mathrm{P}<0.0001)$, and both LDL-C and TC levels significantly increased as TSH level increased, $(\mathrm{R}=0.52, \mathrm{P}<0.0001)$ and $(\mathrm{R}=0.51, \mathrm{P}<0.0001)$ respectively.

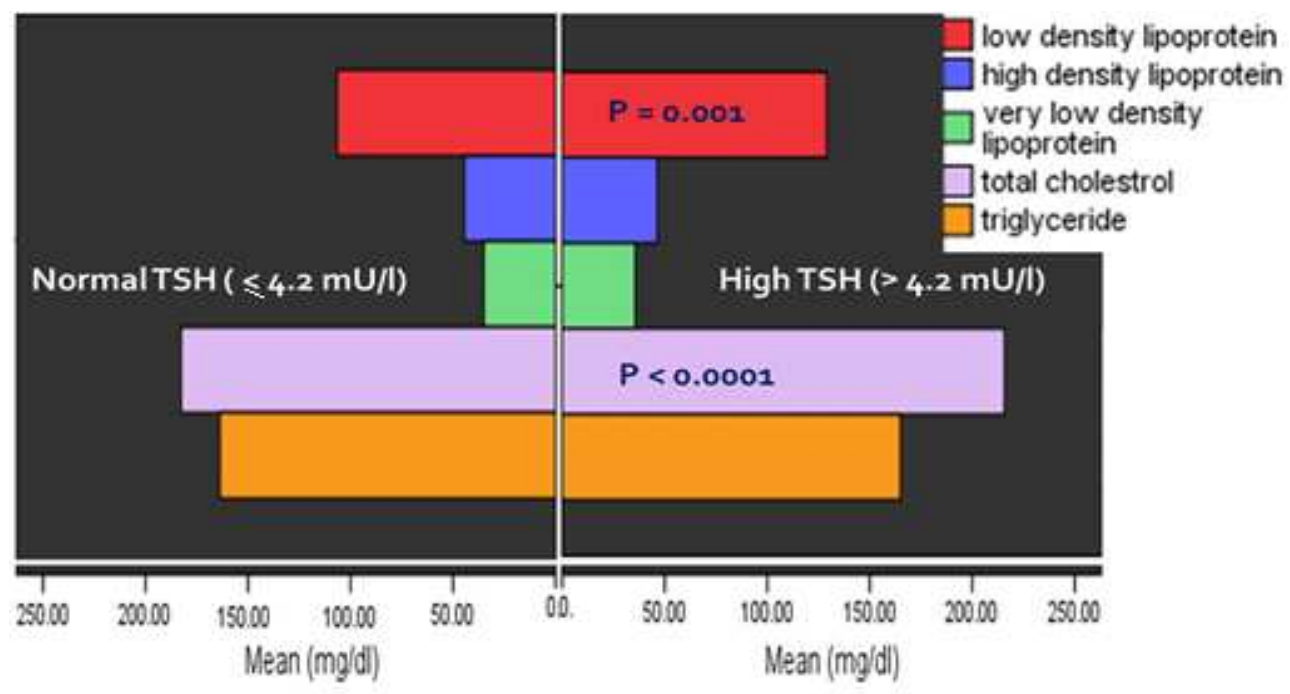

Figure 1. Comparison of lipid profile and TSH control. 
Table 2. Characteristics of hypothyroidism in the study population.

\begin{tabular}{lllll}
\hline Hypothyroidism characteristics & Minimum & Maximum & Mean & Std. deviation \\
\hline Duration of hypothyroidism (years) & 0.5 & 25.0 & 6.1 & 5.6 \\
Last TSH (mU/l) & 0.05 & 100.0 & 19.13 & 29.48 \\
Total L- thyroxine dose (Mg/day) & 25.0 & 200.0 & 98.3 & 40.5 \\
TSH control & TSH $\leq 4.2 \mathrm{mU} / \mathrm{l} \mathrm{N}(\%)$ & & $\mathrm{TSH}>4.2 \mathrm{mU} / \mathrm{N}(\%)$ \\
Mean age (years) in normal and high TSH groups & $38(32.2 \%)$ & $52 \pm 14.1$ & $40(67.8 \%)$ \\
Timing of thyroxine intake & Early morning half hour before breakfast N (\%) & Any other time of the day N (\%) \\
& $90(76.3 \%)$ & & $28(23.7 \%)$ \\
Single or divided dose & Single N (\%) & & Divided N $(\%)$ \\
& $118(100.0 \%)$ & $0.0(0.0 \%)$ \\
\hline
\end{tabular}

The most scored patients' concerns in a descending order were fatigue $(3.12 \pm 0.5)$, neuropathic pain $(3 \pm 0.8)$, lack of weight loss $(2.5 \pm 1.05)$, cold intolerance $(2.49 \pm 0.9)$, breathing problems $(2.47 \pm 1.02)$, and swallowing problems $(2.36 \pm 0.9)$. Other important patients' concerns were skin dryness, constipation, menstrual disturbances, feeling sick and permanent medication. Other patients' concerns like other gynecological, fertility and social concerns were the least scored by the study patients, as shown in figure- 2 .

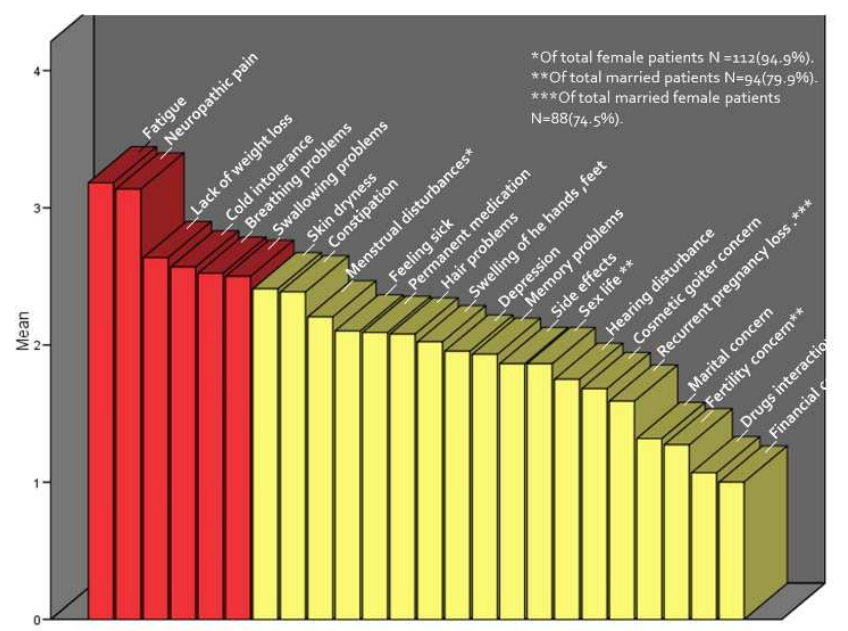

Figure 2. Patients' concerns in a descending order.

When analysis of the patients concerns by Ordinal Logistic Regression Analysis and Independent Student's t test between patients with high TSH $\{(\mathrm{TSH}>4.2 \mathrm{mIU} / 1$, $\mathrm{N}=80(67.8 \%)\}$ and patients with normal TSH $\{(\mathrm{TSH} \leq 4.2$ $\mathrm{mIU} / 1, \mathrm{~N}=38(32.2 \%)\}$, in figure-3, as a response to general health related concerns, we found that fatigue, feeling sick, neuropathic pain, hearing disturbance, cold intolerance, skin dryness, swelling of hands and feet, hair problems, and depression, were scored higher in patients with high TSH. While lack of weight loss, constipation, memory disturbance, and sexual concerns were scored lower in patients with high TSH. However, these concerns did not have significant relation to TSH control except for patients' concerns of feeling $\operatorname{sick}(\mathrm{P}=0.001$, OR $0.27(0.54$ to 2.0$)$, neuropathic pain $(\mathrm{P}=0.01$, OR $0.4(0.17$ to 1.6$))$, cold intolerance $(\mathrm{P}=0.005$, OR $0.35(0.3$ to 1.7$)$, and hair problems $(\mathrm{P}<0.0001$, OR $0.26(0.6$ to 2.1$)$ which were scored significantly higher in patients with high TSH. While lack of weight loss $(\mathrm{P}<0.0001$, OR $8.7(-2.9$ to $(-1.3)$ was significantly scored lower in patients with high TSH than in normal TSH patients.

It was found that swallowing problems, breathing problems, menstrual disturbances, recurrent pregnancy loss and fertility concerns were scored higher, and cosmetic goiter concerns scored lower but not significantly in patients with high TSH. While drugs related concerns, were scored lower in patients with high TSH with the concern of permanent medication $(\mathrm{P}=0.003$ OR $2.7(-1.8$ to -0.35$)$ was significantly lower in this patients group. Social concerns, including marital and financial concerns were scored higher in patients with high TSH and again not significantly, figure- 3 .

Table 3. Comparison of the prevalence of diabetes mellitus and glycemic control in relation to thyroid biochemical control.

\begin{tabular}{llll}
\hline Variable & Normal TSH & High TSH & P value \\
\hline Diabetes N (\%) & $16(57.9)$ & $40(50.0)$ & \\
No diabetes & $22(42.1)$ & $40(50.0)$ & 0.438 \\
Total & $38(100.0)$ & $80(100.0)$ & \\
*HbA1c $\quad<7$ & $4(25.0)$ & $6(15.0)$ & 0.448 \\
N=56 (\%) $\quad$ Mean (SD) & $12(75.0)$ & $34(85.0)$ & 0.6 \\
*Fasting plasma glucose & $154.8(4)$ & $8.6(2.4)$ & 0.6 \\
(mg/dl) mean (SD) & & $162(47.0)$ & 0.6 \\
*Patients with diabetes & & & \\
\hline
\end{tabular}

Table 4. Bivariate correlations of duration of hypothyroidism and patients ages with patient concerns.

\begin{tabular}{lll}
\hline & R value & P value \\
\hline Patients' concerns and disease duration & & \\
Swelling of hands and feet & 0.704 & $<0.0001$ \\
Memory problems & 0.488 & $<0.0001$ \\
Hearing disturbance & 0.388 & $<0.0001$ \\
Hair problems & 0.304 & 0.001 \\
Swallowing problems & 0.287 & 0.002 \\
Constipation & 0.257 & 0.005 \\
Patients' concerns and age & & \\
Memory problems. & 0.625 & $<0.0001$ \\
Swelling of hands and feet & 0.44 & $<0.0001$ \\
Hearing disturbance & 0.37 & $<0.0001$ \\
\hline
\end{tabular}

A bivariate analysis revealed that the duration of the hypothyroidism, the age of the patients, and LDL-C levels and TC correlated significantly with some of the patients concerns. Table-4-shows that swelling of the hands and feet $(\mathrm{R}=0.7 \mathrm{P}<0.0001)$, memory problems $(\mathrm{R}=0.4 \quad \mathrm{P}<0.0001)$, hearing disturbance $(\mathrm{R}=0.38 \mathrm{P}<0.0001)$, hair problems $(\mathrm{R}=0.3 \mathrm{P}=0.001)$, swallowing problems $(\mathrm{R}=0.28 \mathrm{P}=0.002)$ 
and constipation $(\mathrm{R}=0.25 \mathrm{P}=0.005)$ were increased with increased hypothyroidism duration. Memory problems $(\mathrm{R}=0.6 \mathrm{P}<0.0001)$, swelling of the hands and feet $(\mathrm{R}=0.4$ $\mathrm{P}<0.0001)$, and hearing disturbance $(\mathrm{R}=0.37 \mathrm{P}<0.0001)$ were increased as the patient's age increased.

A positive correlation was present between LDL-C level and patients' concerns of cold intolerance $(\mathrm{R}=0.3 \mathrm{P}=0.001)$, hair problems $(\mathrm{R}=0.28 \mathrm{P}=0.003)$, feeling sick $(\mathrm{R}=0.2$ $\mathrm{P}=0.02)$, and neuropathic pain $(\mathrm{R}=0.18 \mathrm{P}=0.04)$. The $\mathrm{TC}$ level also showed a positive correlation with patients' concerns of cold intolerance $(\mathrm{R}=0.3 \mathrm{P}=0$. 001), hair problems $\quad(\mathrm{R}=0.25 \mathrm{P}=0.01)$, neuropathic pain $(\mathrm{R}=0.22$ $\mathrm{P}=0.01)$, and fatigue $(\mathrm{R}=0.2 \mathrm{P}=0.04)$ as shown in table -5 .
Table 5. Bivariate correlation between $L D L-C$ and TC levels and patient concerns.

\begin{tabular}{lll}
\hline & R value & P value \\
\hline Patient concerns and LDL-C & & \\
Cold intolerance & 0.3 & 0.001 \\
Hair problems & 0.28 & 0.003 \\
Feeling sick & 0.2 & 0.02 \\
Neuropathic pain & 0.18 & 0.04 \\
Patient concerns and TC & & \\
Cold intolerance & 0.3 & 0.001 \\
Hair problems & 0.25 & 0.01 \\
Neuropathic pain & 0.22 & 0.01 \\
Fatigue & 0.2 & 0.04 \\
\hline
\end{tabular}

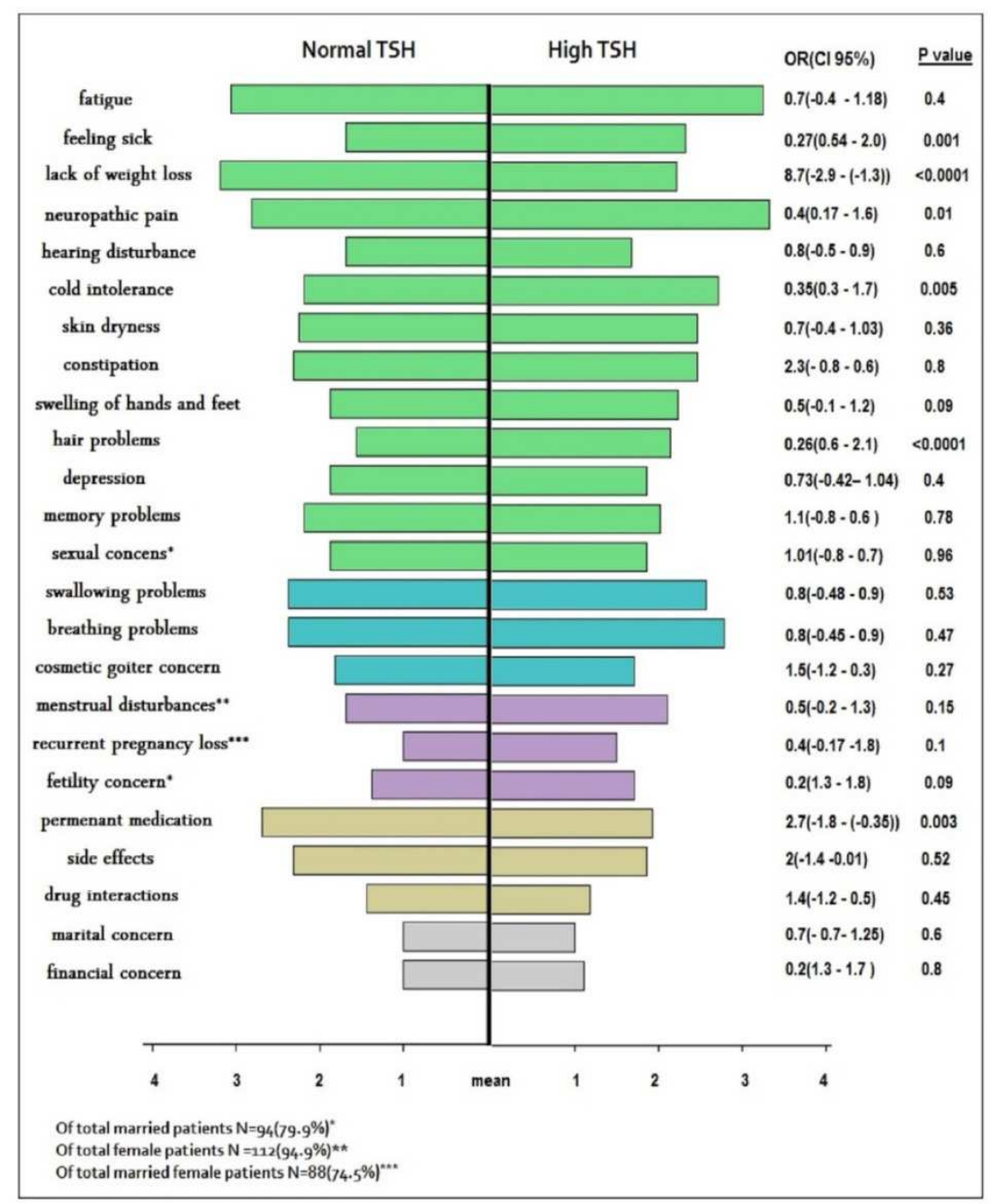

Figure 3. Patients' concerns responses in relation to the thyroid biochemical control.

\section{Discussion}

The study for first time elucidated the concern of the patients with primary hypothyroidism in Iraq. When comparing the findings from our study with observations from other studies which were performed for evaluation of patients' symptoms and other aspects of quality of life in hypothyroidism, a comparable findings appeared with fatigue[1, 12, 13], neuropathic pain [13-17], lack of weight loss $[12,13]$, cold intolerance [18], breathing problems [13, 19], skin dryness [1, 18], constipation [18], hair problems $[12,18]$, cosmetic goiter concern $[12,3]$, and fertility concern $[13,20]$. However, in these studies, lower frequencies were reported in swallowing problems $[13,12$, 13], menstrual disturbances [13], memory problems [1], recurrent pregnancy loss $[13,21]$, and higher frequencies were reported in feeling sick $[12,13]$, swelling of hands and 
feet $[13,18]$, depression, sexual concerns [12], drugs related concerns [13] and social concerns [12, 13].

We found in this study that patients' concerns were variably scored between patients with normal and high TSH level. A significant scoring of feeling sick, neuropathic pain, cold intolerance, and hair problems in patients with high TSH. On the other hand, lack of weight loss and permanent medication significantly scored lower in patients with high TSH than those with normal TSH. While the remaining patients' concerns were not affected significantly by TSH level. These findings were comparable to the results obtained by Bhutani et al [13] who found fatigue, feeling of being sick and lack of wellbeing were scored higher in patients with high TSH. Need for permanent medication and lack of weight loss were sources of relatively greater concern for the patients with normal TSH. No significant correlation was between other patients' concerns and TSH control.

Saravaven et al[6] performed a community based study in which they found that hypothyroid patients despite treatment and achievement of normal TSH values were more likely to complain of difficulty in remembering, fatigue, putting on weight, and inability to think clearly, a finding comparable to our study. Canaris et al [1] and Zulewski et al [18] both found a weak correlation between hypothyroid symptoms and TSH level, however, Zulewski et al found an excellent correlation between TC levels as a marker of peripheral thyroxine action and patients' symptoms. In our study, significant correlation was present between TC level and patients' concerns of cold intolerance, hair problems, neuropathic pain, and fatigue, and between LDL-c level and cold intolerance, hair problems, feeling sick, and neuropathic pain. These findings suggest the persistence of patients' concerns despite the achievement of TSH control "biochemical control". Some patients with severe biochemical hypothyroidism had only mild symptoms, whereas others with mild biochemical changes had severe clinical manifestations [18]. This may be explained by the concept of tissue hypothyroidism or hypothyroidism at the cellular level $[18,22]$. The pituitary gland is thought to have a higher sensitivity to thyroxine therapy than other parts of the body [22], and maintains higher level of T3 [23] resulting in euthyroid response in the pituitary with normal TSH while other tissues remain hypothyroid at cellular level [22].

False overestimation of thyroid function is another explanation which is caused by diurnal variation in TSH level. This can happen if TSH assay is done during early afternoon, when they are at their lowest [24].

Also it is generally thought that some patients feels better when they are slightly hyperthyroid with a higher well-being score were obtained when TSH level was below $0.2 \mathrm{mIU} / 1$ [25]. While in other study, some patients feels better on TSH level below $2.5 \mathrm{mIU} / 1$ [26].

Finally because many of hypothyroid symptoms and complains are common in the general population it might be expected that they would occur in some hypothyroid patients even after appropriate thyroid hormone replacement,[27] so that some patients with persistent symptoms despite normal TSH may have co-morbid conditions like diabetes mellitus, depression, hypertension, coronary heart disease, vitamin D deficiency, celiac disease, menopause, anemia, sleep apnea, hyponatremia, hypocalcemia, and other endocrine disorders, which are more common in the hypothyroid population [6-8, $10,11,28-29]$.Beside these conditions, the use of certain anti-diabetic, antidepressant and anti-hypertensive medications [7].

It was also notable in this study that both duration of the hypothyroidism and the age of the patients had an effect on patients' concerns. As the duration increased, patients' concerns of swelling of the hands and feet, memory problems, hearing disturbances, hair problems, swallowing problems and constipation increased. While with increased patient's age, memory problems, swelling of hands and feet, and hearing disturbance increased. Bhutani et al [13], found a positive correlation between the duration of the hypothyroidism and swelling of hands and feet and swallowing problems. These findings can be explained by the fact that these hypothyroid manifestations may be developed as a result of deposition of hyaluronic acid in the entire gastrointestinal tract [30-32], middle ear [33, 34], and other body tissues [35] which does not occur in the short term and increase in a time dependent manner [36], resulting in a progressive increase in swelling of hands and feet, hearing disturbances, hair problems, swallowing problems and constipation with increase disease duration. Also, it had been found that memory decline in hypothyroidism has a progressive nature with increase disease duration, and may not be reversed with therapy [37] Besides, both memory and hearing decline may occur as a part of ageing process and can be accelerated by hypothyroidism [38] which can explain the increased concerns in these symptoms with increased age.

\section{Limitations}

No available questionnaire has the potential to cover all aspects relevant to patients in longitudinal studies, they all lack a thorough validation.

Single center, small sample size, and lack of control are limiting factors in this study.

We were unable to perform analysis based on gender due to a small number of the male patients.

No work was done to assess markers of tissue hypothyroidism nor to delineate the exact contribution of associated medical conditions on patient's symptoms due frequent unavailability of the tests.

\section{Conclusion}

These findings suggest that we cannot rely on the basis of TSH alone as a marker of optimal treatment outcome as it does not reflect the concern status of the patients, but we have to achieve patient symptomatic relief and satisfaction. 


\section{Contributions}

All authors contributed equally to the article.

\section{Acknowledgement}

The authors would like to thank all medical staff of AlFaiha Specialized Diabetes, Endocrine and Metabolism Center (FDEMC) for their efforts.

\section{References}

[1] Canaris GJ, Manowitz NR, Mayor G, Ridgway EC. The Colorado thyroid disease prevalence study. Arch Intern Med. 2000 Feb 28; 160(4): 526-34.

[2] Wilson GR, Curry RW Jr. Subclinical thyroid disease. Am Fam Physician. 2005 Oct 15; 72(8): 1517-24.

[3] Meier C, Staub JJ, Roth CB, Guglielmetti M, Kunz M, Miserez AR, Drewe J, Huber P, Herzog R, Müller B.TSHcontrolled L-thyroxine therapy reduces cholesterol levels and clinical symptoms in subclinical hypothyroidism: a double blind, placebo-controlled trial (Basel Thyroid Study). J Clin Endocrinol Metab. 2001 Oct; 86(10): 4860-6.

[4] Robert ND. Psychological problems in thyroid disease. $\mathrm{Br}$ Thyroid Found Newsl 1996; 18: 3.

[5] Dale J, Daykin J, Holder R, Sheppard MC, Franklyn JA. Weight gain following treatment of hyperthyroidism. Clin Endocrinol (Oxf). 2001 Aug; 55(2): 233-9.

[6] Saravanan P, Chau WF, Roberts N, Vedhara K, Greenwood R, Dayan CM. Clin Endocrinol (Oxf). Psychological well-being in patients on 'adequate' doses of 1-thyroxine: results of a large, controlled community-based questionnaire study. 2002 Nov; 57(5): 577-85.

[7] Kalra S, Kalra B, Khandelwal SK. Vitamin D status in well controlled hypothyroid patients in Haryana, India. Thyroid Res Pract 2011; 8: 12-6.

[8] Collins D, Wilcox R, Nathan M, Zubarik R. Celiac disease and hypothyroidism. Am J Med. 2012 Mar; 125(3): 278-82. doi: 10.1016/j.amjmed. 2011. 09. 003.

[9] Erdogan M, Kösenli A, Ganidagli S, Kulaksizoglu M. Characteristics of anemia in subclinical and overt hypothyroid patients. Endocr J. 2012; 59(3): 213-20.

[10] Hernández Valencia M1, Córdova Pérez N, Zárate A, Basurto L, Manuel Apolinar L, Ruiz M, Vargas C, Vargas A. Hypothyroidism associated to menopause symptoms worsening change with thyroid substitution therapy. Ginecol Obstet Mex. 2008 Oct; 76(10): 571-5.

[11] Bahammam SA, Sharif MM, Jammah AA, Bahammam AS. Prevalence of thyroid disease in patients with obstructive sleep apnea. Respir Med. 2011 Nov; 105(11): 1755-60. doi: 10.1016/j.rmed. 2011.07.007.

[12] Watt T, Hegedüs L, Rasmussen AK, Groenvold M, Bonnema SJ, Bjorner JB, Feldt-Rasmussen U. Which domains of thyroid-related quality of life are most relevant? Patients and clinicians provide complementary perspectives. Thyroid. 2007 Jul; 17(7): 647-54.

[13] Bhutani S, Bhutani J, Balhara YP, Kalra S. Patient concerns in treated hypothyroidism: A cross-sectional evaluation. Thyroid
Res Pract 2013; 10: 72-7.

[14] Watt T, Groenvold M, Rasmussen AK, Bonnema SJ, Hegedüs L, Bjorner JB, Feldt-Rasmussen U. Quality of life in patients with benign thyroid disorders. A review. Eur J Endocrinol. 2006 Apr; 154(4): 501-10.

[15] Duyff RF, Van den Bosch J, Laman DM, van Loon BJ, Linssen WH. Neuromuscular findings in thyroid dysfunction: a prospective clinical and electrodiagnostic study. J Neurol Neurosurg Psychiatry. 2000 Jun; 68(6): 750-5.

[16] Kececi H, Degirmenci Y. Hormone replacement therapy in hypothyroidism and nerve conduction study. Neurophysiol Clin. 2006 Mar-Apr; 36(2): 79-83.

[17] Beghi E, Delodovici ML, Bogliun G, Crespi V, Paleari F, Gamba P, Capra M, Zarrelli M. Hypothyroidism and polyneuropathy. J Neurol Neurosurg Psychiatry. 1989 Dec; 52(12): 1420-3.

[18] Zulewski H, Müller B, Exer P, Miserez AR, Staub JJ. Estimation of tissue hypothyroidism by a new clinical score: evaluation of patients with various grades of hypothyroidism and controls. J Clin Endocrinol Metab. 1997 Mar; 82(3): 771-6.

[19] Misiolek M, Marek B, Namyslowski G, Scierski W, ZwirskaKorczala K, Kazmierczak-Zagorska Z, Kajdaniuk D, Misiolek H. Sleep apnea syndrome and snoring in patients with hypothyroidism with relation to overweight. J Physiol Pharmacol. 2007 Mar; 58 Suppl 1: 77-85.

[20] Joshi JV, Bhandarkar SD, Chadha M, Balaiah D, Shah R. Menstrual irregularities and lactation failure may precede thyroid dysfunction or goitre. J Postgrad Med. 1993 Jul-Sep; 39(3): 137-41.

[21] Wilcox AJ, Weinberg CR, O'Connor JF, Baird DD, Schlatterer JP, Canfield RE, Armstrong EG, Nisula BC. Incidence of early loss of pregnancy. N Engl J Med. 1988 Jul 28; 319(4): 189-94.

[22] Staub JJ, Althaus BU, Engler H, Ryff AS, Trabucco P, Marquardt K, Burckhardt D, Girard J, Weintraub BD. Spectrum of subclinical and overt hypothyroidism: effect on thyrotropin, prolactin, and thyroid reserve, and metabolic impact on peripheral target tissues. Am J Med. 1992 Jun; 92(6): 631-42.

[23] Larsen PR, Silva JE, Kaplan MM. Relationships between circulating and intracellular thyroid hormones: physiological and clinical implications. Endocr Rev. 1981 Winter; 2(1): 87102.

[24] Sturgess I, Thomas SH, Pennell DJ, Mitchell D, Croft DN.Diurnal variation in TSH and free thyroid hormones in patients on thyroxine replacement. Acta Endocrinol (Copenh). 1989 Nov; 121(5): 674-6.

[25] Carr D, McLeod DT, Parry G, Thornes HM. Fine adjustment of thyroxine replacement dosage: comparison of the thyrotrophin releasing hormone test using a sensitive thyrotrophin assay with measurement of free thyroid hormones and clinical assessment. Clin Endocrinol (Oxf). 1988 Mar; 28(3): 325-33.

[26] Todd CH.Management of thyroid disorders in primary care: challenges and controversies. Postgrad Med J. 2009 Dec; 85(1010): 655-9. doi: 10.1136/pgmj. 2008.077701.

[27] Kaplan MM, Sarne DH, Schneider AB. In search of the impossible dream? Thyroid hormone replacement therapy that treats all symptoms in all hypothyroid patients. J Clin Endocrinol Metab. 2003 Oct; 88(10): 4540-2. 
[28] Erdogan M, Kösenli A, Ganidagli S, Kulaksizoglu M. Characteristics of anemia in subclinical and overt hypothyroid patients. Endocr J. 2012; 59(3): 213-20.

[29] Tunbridge WM, Evered DC, Hall R, Appleton D, Brewis M, Clark F, Evans JG, Young E, Bird T, Smith PA. The spectrum of thyroid disease in a community: the Whickham survey. Clin Endocrinol (Oxf). 1977 Dec; 7(6): 481-93.

[30] Shafer RB, Prentiss RA, Bond JH. Gastrointestinal transit in thyroid disease. Gastroenterology. 1984 May; 86(5 Pt1): 852-5.

[31] Kahraman H, Kaya N, Demirçali A, Bernay I, Tanyeri F.Gastric emptying time in patients with primary hypothyroidism. Eur J Gastroenterol Hepatol. 1997 Sep; 9(9): 901-4.

[32] Safer JD. Thyroid hormone action on skin. Dermatoendocrinol. 2011 Jul; 3(3): 211-5. doi: 10.4161/derm. 3. 3. 17027.

[33] Malik V, Shukla GK, Bhatia N. Hearing profile in hypothyroidism. Indian J Otolaryngol Head Neck Surg. 2002 Oct; 54(4): 285-90. doi: 10.1007/BF02993744.

[34] Smith TJ, Bahn RS, Gorman CA. Connective tissue, glycosaminoglycans, and diseases of the thyroid. Endocr Rev. 1989 Aug; 10(3): 366-91.

[35] Goto S, Billmire DF, Grosfeld JL. Hypothyroidism impairs colonic motility and function. An experimental study in the rat. Eur J Pediatr Surg. 1992 Feb; 2(1): 16-21.

[36] Smith TJ, Murata Y, Horwitz AL, Philipson L, Refetoff S. Regulation of glycosaminoglycan synthesis by thyroid hormone in vitro. J Clin Invest. 1982 Nov; 70(5): 1066-73.

[37] Mennemeier M, Garner RD, Heilman KM. Memory, mood and measurement in hypothyroidism. $J$ Clin Exp Neuropsychol. 1993 Sep; 15(5): 822-31.

[38] Hedden T, Gabrieli JD. Insights into the ageing mind: a view from cognitive neuroscience. Nat Rev Neurosci. 2004 Feb; 5(2): 87-96. 